OPEN ACCESS

Edited by:

Ganglong Yang,

Jiangnan University, China

Reviewed by:

Yingwei Hu,

Johns Hopkins University,

United States

Heeyoun Hwang,

Korea Basic Science Institute (KBSI),

South Korea

${ }^{*}$ Correspondence:

Weijie Qin

aunp_dna@126.com

Specialty section:

This article was submitted to

Analytical Chemistry,

a section of the journal

Frontiers in Chemistry

Received: 04 March 2021

Accepted: 06 April 2021

Published: 26 April 2021

Citation:

Fan Z, Liu T, Zheng F, Qin W and

Qian X (2021) An Ultrafast

$\mathrm{N}$-Glycoproteome Analysis Method

Using Thermoresponsive Magnetic

Fluid-Immobilized Enzymes.

Front. Chem. 9:676100

doi: $10.3389 /$ fchem.2021.676100

\section{An Ultrafast $\mathrm{N}$-Glycoproteome Analysis Method Using Thermoresponsive Magnetic Fluid-Immobilized Enzymes}

\author{
Zhiya Fan ${ }^{1}$, Tong Liu ${ }^{1}$, Fei Zheng ${ }^{1}$, Weijie Qin ${ }^{1,2 *}$ and Xiaohong Qian ${ }^{1}$ \\ ${ }^{1}$ State Key Laboratory of Proteomics, National Center for Protein Sciences (Beijing), Beijing Proteome Research Center, \\ Beijing, China, ${ }^{2}$ College of Basic Medicine, Anhui Medical University, Hefei, China
}

$\mathrm{N}$-Glycosylation is one of the most common and important post-translational modification methods, and it plays a vital role in controlling many biological processes. Increasing discovery of abnormal alterations in $N$-linked glycans associated with many diseases leads to greater demands for rapid and efficient $N$-glycosylation profiling in large-scale clinical samples. In the workflow of global $\mathrm{N}$-glycosylation analysis, enzymatic digestion is the main rate-limiting step, and it includes both protease digestion and peptide-N4-(N-acetyl-beta-glucosaminyl) asparagine amidase (PNGase) $\mathrm{F}$ deglycosylation. Prolonged incubation time is generally required because of the limited digestion efficiency of the conventional in-solution digestion method. Here, we propose novel thermoresponsive magnetic fluid (TMF)-immobilized enzymes (trypsin or PNGase F) for ultrafast and highly efficient proteome digestion and deglycosylation. Unlike other magnetic material-immobilized enzymes, TMF-immobilized enzymes display a unique temperature-triggered magnetic response behavior. At room temperature, a TMF-immobilized enzyme completely dissolves in an aqueous solution and forms a homogeneous system with a protein/peptide sample for efficient digestion but cannot be separated by magnetic force because of its excellent water dispersity. Above its lower critical solution temperature (LCST), thermoflocculation of a TMF-immobilized enzyme allows it to be easily recovered by increasing the temperature and magnetic force. Taking advantage of the unique homogeneous reaction of a TMF-immobilized enzyme, both protein digestion and glycopeptide deglycosylation can be finished within $3 \mathrm{~min}$, and the whole sample processing time can be reduced by more than 20 times. The application of a TMF-immobilized enzyme in large-scale profiling of protein $\mathrm{N}$-glycosylation in urine samples led to the successful identification of 2,197 N-glycopeptides and further demonstrated the potential of this strategy for fast and high-throughput analysis of $\mathrm{N}$-glycoproteome in clinical samples.

Keywords: urine proteomics, protein glycosylation, immobilized enzyme, thermo-responsiveness, magnetic fluid 


\section{INTRODUCTION}

Glycosylation is one of the most prominent post-translational modification methods for proteins (Stadlmann et al., 2017; Huang et al., 2019). As a major type, $N$-glycosylation has a wide range of functions that greatly amplifies the diversity of proteins (Hart and Copeland, 2010; Yang et al., 2020). From the general biological process, such as cell adhesion and signal transduction, to specific functions of proteins like folding and stability, the complexity imparted to a proteome by $\mathrm{N}$ glycosylation is immense (Schjoldager et al., 2020). Moreover, the $\mathrm{N}$-glycans biosynthesis process is very sensitive to the physiological and pathological states in cells (Mereiter et al., 2019; Dong et al., 2020), and glycoproteins are a main type of current therapeutic targets and disease biomarkers (Pan et al., 2020; Zhao et al., 2020). Fueled by the increasing discovery of disease-related $\mathrm{N}$-glycans alterations, the interest in largescale $N$-glycosylation profiling in clinical samples is proliferating. Urine, as a reflection of body changes, is considered as an ideal source for biomarker discovery ( $\mathrm{Wu}$ and Gao, 2015). It can be obtained in a non-invasive manner with a relatively narrower protein dynamic range and much less interference by high-abundance proteins compared with that of plasma/serum (Zhao et al., 2017). Therefore, rapid and in-depth analysis of $N$ glycoproteome from a large cohort of urine samples is highly desirable for a clinical study.

In mass spectrometry-based shotgun $N$-glycoproteome analysis, enzymatic digestion of proteins and release of $N$ glycans are regarded as key steps, which are generally performed using a solution. However, because only a small amount of enzyme is used and digestion efficiency is limited in solutionbased digestion, prolonged incubation time is needed, which highly limits sample throughput (Qin et al., 2012). To address these problems, various kinds of the immobilized enzyme have been developed with the advantages of reducing enzyme self-digestion, stabilizing enzymatic activity, and allowing higher enzyme concentration for shorter digestion time (Mateo et al., 2007). In contrast with conventional in-solution digestion, an immobilized enzyme for in situ digestion can be easily separated from the digestion system and reused. Various supports have been proven to be feasible for enzyme immobilization, such as nanomaterials (Sharifi et al., 2020), porous silicon matrices (Létant et al., 2004), porous polymer monoliths (Krenkova et al., 2009), sol-gel supports (Yuce-Dursun et al., 2016), membranes (Luo et al., 2014), magnetic beads (Zhao et al., 2015; Fauser et al., 2020), and graphene oxide (Yuan et al., 2017). Although the required digestion time is obviously decreased using these reagents, because of the insolubility of reported supporting materials, digestion is processed under solid-liquid heterogeneous conditions that may limit reaction efficiency. Therefore, a new immobilized enzyme with homogeneous digestion and heterogeneous separation characteristics has high demand.

In this study, we developed a new type of immobilized enzyme reagent based on thermoresponsive magnetic fluid (TMF) with a lower critical solution temperature (LCST) in an aqueous solution (Supplementary Figure 1). To the best of our knowledge, this is the first study to immobilize trypsin or PNGase F in TMF. TMF is composed of thermoresponsive polymer chains grafted from the surface of a small magnetic $\mathrm{Fe}_{3} \mathrm{O}_{4}$ core $(\sim 10 \mathrm{~nm})$, via in situ growth using the surfaceinitiated atom transfer radical polymerization (SI-ATRP) technique. Thermoresponsive polymer chains are copolymerized using $N$-isopropylacrylamide (NIPAM) (Zhang et al., 2017) and undecylenic aldehyde (UnAl), which provides TMF with thermoresponsive property, water solubility, and reactivity with enzymes. Unlike other magnetic material-immobilized enzymes, TMF-immobilized enzymes exhibit a unique temperature-triggered magnetic response behavior. When the temperature is lower than LCST, the TMF-immobilized enzyme completely dissolves in an aqueous solution, and digestion is performed under homogeneous conditions, which therefore avoids interfacial mass transfer resistance in the two-phase heterogeneous system, and enhances enzyme-substrate interaction and reaction efficiency. After digestion and raising the temperature above LCST, the TMFimmobilized enzyme can be easily recovered by heat-triggered polymer thermoflocculation and magnetic separation (see Supplementary Video 1). Taking advantage of homogeneous reaction and high enzyme loading, either protein digestion or glycopeptide deglycosylation can be finished within $3 \mathrm{~min}$, and the whole sample processing time can be reduced by more than 20 times (Figure 1) with digestion efficiency comparable to that of conventional in-solution overnight digestion. The successful application of TMF-immobilized enzymes in large-scale $\mathrm{N}$-glycosylation identification using complex protein samples further demonstrated the potential of this strategy for high-throughput analysis of $\mathrm{N}$-glycoproteome in clinical samples.

\section{MATERIALS AND METHODS}

\section{Preparation of TMF-Immobilized Enzyme Synthesis of Oleic Acid-Coated Magnetic Nanoparticles (OA-Coated MNPs)}

Oleic acid (OA)-coated magnetic $\mathrm{Fe}_{3} \mathrm{O}_{4}$ nanoparticles were synthesized according to the previously reported method (Sun et al., 2006) with minor modifications. $\mathrm{FeSO}_{4} \cdot 7 \mathrm{H}_{2} \mathrm{O}(1.18 \mathrm{~g}$, $4.24 \mathrm{mmol})$ and $\mathrm{FeCl}_{3} \cdot 6 \mathrm{H}_{2} \mathrm{O}(2.05 \mathrm{~g}, 7.58 \mathrm{mmol})$ were dissolved in $50 \mathrm{ml}$ deionized water with vigorous stirring. The solution was heated at $60^{\circ} \mathrm{C}$, and then $25 \mathrm{ml} 25 \%$ (w/w) $\mathrm{NH}_{3} \cdot \mathrm{H}_{2} \mathrm{O}$ was added dropwise. The solution color changed from orange to black, leading to a black precipitate. Then, $0.5 \mathrm{ml} \mathrm{OA}$ was added dropwise into the dispersion slowly at $80^{\circ} \mathrm{C}$ for $1 \mathrm{~h}$. The whole process was carried out in a nitrogen atmosphere. Next, magnetic nanoparticles were extracted from water into toluene. Water dispersion 50 and $50 \mathrm{ml}$ toluene was mixed in a $250-\mathrm{ml}$ extractor. After adding a small amount of $\mathrm{NaCl}$, magnetic nanoparticles transferred into the toluene phase with good dispersity under the coating of OA. Finally, the toluene dispersion was evaporated to remove the solvent under reduced pressure and dried under vacuum. The content of OA-coated MNPs was redissolved into toluene to $10 \mathrm{mg} / \mathrm{ml}$. 


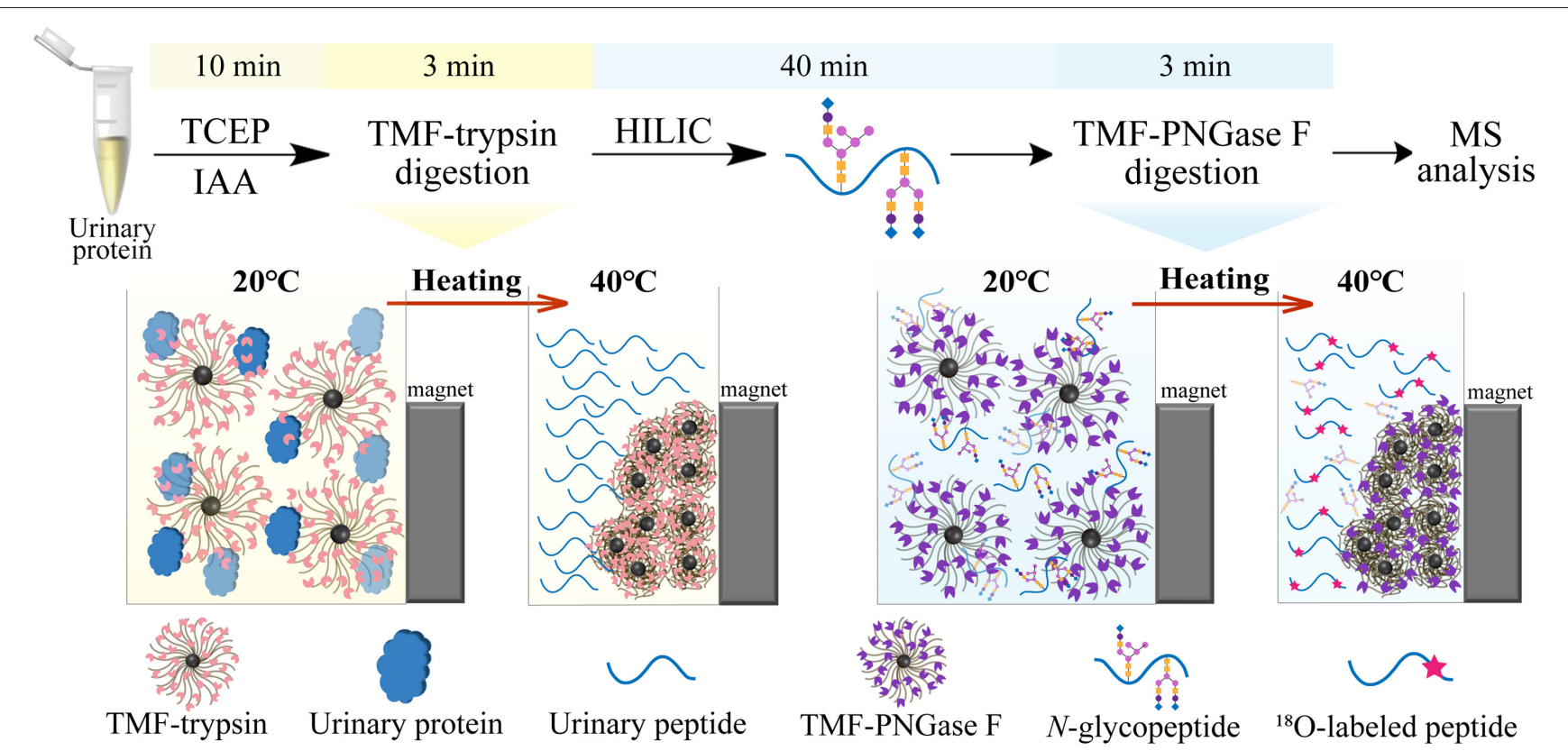

FIGURE 1 | Workflow of ultrafast N-glycoprotein analysis by TMF-trypsin digestion and TMF-PNGase F deglycosylation.

\section{Synthesis of Initiator}

As an initiator, 3-(2-bromoisobutyramido)propyl(triethoxy)silane (BIBAPTES) was synthesized as follows: $\alpha$ bromoisobutyryl bromide $(0.1 \mathrm{ml}, 0.8 \mathrm{mmol})$ was added dropwise to a cold solution of 3-aminopropyltriethoxysilane (ATEPS) $(0.18 \mathrm{ml}, 0.8 \mathrm{mmol})$ in dry toluene $(10 \mathrm{ml})$ with triethylamine (TEA) $(0.12 \mathrm{ml}, 0.8 \mathrm{mmol})$ at $0^{\circ} \mathrm{C}$. The mixture was magnetically stirred for $3 \mathrm{~h}$ at $0^{\circ} \mathrm{C}$ and further stirred for $10 \mathrm{~h}$ at room temperature to complete the reaction. The precipitate (triethylammonium bromide) was filtered off. The filtrate was evaporated under reduced pressure to remove unreacted TEA and dried under vacuum.

\section{Synthesis of Initiator-Grafted Magnetic Nanoparticles} Initiator-grafted magnetic nanoparticles were synthesized by ligand exchange reaction: BIBAPTES $(0.05 \mathrm{ml})$, TEA $(1 \mathrm{ml})$, and OA-coated MNPs $(50 \mathrm{mg}$ ) were added into $15 \mathrm{ml}$ dry toluene in a nitrogen atmosphere. The mixture was stirred for $48 \mathrm{~h}$ at room temperature. Next, the mixture was centrifuged to remove salts (triethylammonium oleate). The supernatant was centrifuged at $20,000 \mathrm{~g}$ for $60 \mathrm{~min}$, washed three times with toluene to remove un-grafted initiators and unreacted TEA, and dried under vacuum.

\section{Synthesis of PNIPAM-b-PUnAl via Surface Initiated ATRP on Magnetic Nanoparticles}

Initiator-grafted magnetic nanoparticles $60 \mathrm{mg}$ were resuspended in $20 \mathrm{ml}$ isopropanol/water (v/v: 3/1), and then $N$ isopropylacrylamide (NIPAM) $(1 \mathrm{~g}, 8.85 \mathrm{mmol})$, purified $\mathrm{Cu}(\mathrm{I}) \mathrm{Br}$ (240 $\mathrm{mg}, 1.68 \mathrm{mmol})$, and Tris (2-dimethylaminoethyl)amine $\left(\mathrm{Me}_{6} \mathrm{TREN}\right)(0.44 \mathrm{ml}, 1.68 \mathrm{mmol})$ were added in a nitrogen atmosphere. The mixture was agitated at room temperature for
6-8 $\mathrm{h}$, and then $\mathrm{UnAl}(1.4 \mathrm{ml}, 7.08 \mathrm{mmol})$ was added and reacted for a further $12-18 \mathrm{~h}$ at room temperature. Finally, the magnetic fluid with thermoresponsive property and aldehyde groups was obtained after dialysis for $48 \mathrm{~h}$.

\section{Trypsin or PNGase F Immobilization on TMF and Measurement of Enzyme Loading Capacity}

Trypsin (or PNGase F) was immobilized on the PNIPAM$b$-PUnAl-grafted magnetic nanoparticles via Borch reduction between the aldehyde groups of the copolymer chains and the free amino groups of trypsin (or PNGase F). Typically, $8 \mathrm{mg}$ modified magnetic nanoparticles were dispersed in $1 \mathrm{ml}$ PBS ( $\mathrm{pH}$ 7.4) containing $1 \mathrm{mg}$ trypsin (or 1,500 UPNGase F) and $5 \mathrm{mg} \mathrm{NaBH}{ }_{3} \mathrm{CN}$. Next, the mixture was agitated at $4^{\circ} \mathrm{C}$ for $12 \mathrm{~h}$. After the reaction, the mixture was heated to $32^{\circ} \mathrm{C}$ to allow the magnetic nanoparticles to flocculate, and trypsin (or PNGase F)-attached magnetic nanoparticles were then collected with a magnet. The collected magnetic nanoparticles were washed three times by adding a $1 \mathrm{ml} 50 \mathrm{mM} \mathrm{NH} \mathrm{HCO}_{3}$ aqueous solution and repeating dispersion and flocculation. The enzyme loading capability of TMF was determined by HPLC via calculation of the difference in the peak area of the bovine serum albumin (BSA) solution before and after immobilization, which is similar to that of trypsin or PNGase F.

\section{TMF-Trypsin or Free Trypsin Digestion of Standard Protein and Urinary Proteins}

This study was approved by the Institutional Review Board of the Tianjin Baodi Hospital, and all donors approved the use of their urine samples. Standard protein (BSA) was dissolved in $50 \mathrm{mM}$ ammonium bicarbonate $(\mathrm{ABC}, \mathrm{pH}=8)$. Mid-stream samples of morning urine were collected and centrifuged at $12,000 \mathrm{~g}$ and 
$4^{\circ} \mathrm{C}$ for $30 \mathrm{~min}$ to remove cell debris. The urinary protein was precipitated by ice-cooled acetone and dissolved in a lysis buffer ( $8 \mathrm{M}$ urea, $100 \mathrm{mM}$ Tris- $\mathrm{HCl}, \mathrm{pH}=8$ ) to a concentration of 1 $\mathrm{mg} / \mathrm{ml}$. Each sample was heated for $10 \mathrm{~min}$ at $95^{\circ} \mathrm{C}$ to denature. Then, TCEP $(10 \mathrm{mM})$ reduction and CAA $(40 \mathrm{mM})$ alkylation were performed. For TMF-trypsin digestion, $1 \mathrm{~mL}$ of the protein solution was mixed with TMF-trypsin and incubated for $3 \mathrm{~min}$ at room temperature. After digestion, the immobilized trypsin was retained by a heating-magnet process, and the supernatant was collected for mass spectrometry analysis. The TMF-trypsin materials can be reused after washing them three times with $50 \mathrm{mM}$ ABC. For free trypsin digestion, first, the protein solution was diluted to reduce the urea concentration to $1 \mathrm{M}$. Then, free trypsin was introduced into the denatured protein solution at a substrate to enzyme ratio $(\mathrm{w} / \mathrm{w})$ of $50: 1$ and incubated at $37^{\circ} \mathrm{C}$ for $16 \mathrm{~h}$. After digestion, $2 \mu \mathrm{l}$ of formic acid was added to terminate the reaction, and the supernatant was collected for mass spectrometry analysis.

\section{HILIC Enrichment of Urinary N-Glycopeptides}

Zwitterionic hydrophilic interaction liquid chromatography (ZIC-HILIC) materials ( $5 \mathrm{mg}$ ) were washed with a $200 \mu \mathrm{l}$ binding buffer ( $80 \%$ ACN, 1\% TFA) three times and incubated with $80 \mu \mathrm{g}$ urinary peptides (TMF-trypsin digestion products) for $0.5 \mathrm{~h}$. After that, a $600 \mu \mathrm{l}$ binding buffer was used to remove non-specifically absorbed peptides. Finally, the $N$-glycopeptides were eluted using a $200 \mu$ l elution buffer $(0.1 \%$ FA) and then vacuum-dried.

\section{TMF-PNGase F or Free PNGase F Deglycosylation of Standard Glycoproteins and Urinary Glycopeptides}

Standard glycoprotein RNase B $(10 \mu \mathrm{g} / \mu \mathrm{l})$ was dissolved in deionized water and heated at $95^{\circ} \mathrm{C}$ for $10 \mathrm{~min}$ to denature. Then, TCEP $(10 \mathrm{mM})$ reduction and CAA $(40 \mathrm{mM})$ alkylation were performed. Urinary $\mathrm{N}$-glycopeptides were obtained according to HILIC Enrichment of Urinary N-Glycopeptides and dissolved in $\mathrm{H}_{2}^{18} \mathrm{O}$. For TMF-PNGase F deglycosylation, $4 \mu \mathrm{l}$ of the protein solution was mixed with $1 \mathrm{ml}$ TMF-PNGase $\mathrm{F}$ and incubated for $3 \mathrm{~min}$ at room temperature. The immobilized PNGase F was retained by a heating-magnet process, and the supernatant was collected for mass spectrometry analysis. The TMF-PNGase F materials can be reused after washing them three times with deionized water (or $\mathrm{H}_{2}^{18} \mathrm{O}$ ). For in-solution deglycosylation, PNGase $\mathrm{F}$ was introduced to the protein solution at a substrate to enzyme ratio $(\mathrm{w} / \mathrm{w})$ of $10: 1$ and incubated at $37^{\circ} \mathrm{C}$ for $16 \mathrm{~h}$. No further pre-process was required for in-solution digestion before mass spectrometry analysis.

\section{Mass Spectrometry Analysis MALDI-TOF MS}

For (glyco)protein analysis, equivalent volumes of the protein solution, aqueous 2\% trifluoroacetic acid (TFA), and a 2,5dihydroxyacetophenone (2, 5-DHAP) matrix were mixed by pipetting up and down until the liquid became cloudy. The mixture $(1 \mu \mathrm{l})$ was applied onto a matrix-assisted laser desorption ionization (MALDI) plate and air-dried. For tryptic peptides and glycopeptides analysis, equivalent volumes of the peptide solution and a 2,4-dihydroxybenzoic (DHB) matrix were mixed, deposited onto a MALDI plate $(1 \mu \mathrm{l})$, and air-dried. A MALDItime of flight (TOF) mass spectrometry (MS) instrument (Bruker, Bremen, Germany) performed in positive ion mode with a nitrogen pulsed laser $(337 \mathrm{~nm})$ was used for measurements.

\section{LC-MS/MS}

The resulting peptide mixture was analyzed using an Orbitrap Fusion Lumos Tribrid mass spectrometer coupled with an EASYnLC 1,000 nano-LC system (ThermoFisher Scientific, Waltham, MA, USA). Peptide separation was performed on a $15-\mathrm{cm}$ length reverse phase $\mathrm{C}_{18}$ column (150 nm id, $1.9 \mu \mathrm{m}, 100 \AA$ ) using A and $B$ buffers (buffer A:0.1\% formic acid in water; buffer B:0.1\% formic acid in acetonitrile) at a constant flow rate of $600 \mathrm{nl}$ $\min ^{-1}$. The gradient was set as follows: $7-15 \% \mathrm{~B}$ for $7 \mathrm{~min}$, $15-25 \%$ B for $37 \mathrm{~min}, 25-40 \%$ B for $20 \mathrm{~min}$, and $40-100 \%$ B for $7 \mathrm{~min}$. The dynamic exclusion duration of data-dependent MS2 acquisition (DDA) is $18 \mathrm{~s}$. For MS1 scan, mass spectra were acquired in the positive-ion mode over the range of 300-1,400 $\mathrm{m} / \mathrm{z}$ with a resolution of 120,000 and a maximum ion injection time of $50 \mathrm{~ms}$. MS2 spectra were acquired with an automatic gain control target value of 5.e3 and a maximum injection time of $35 \mathrm{~ms}$ with higher-energy collision dissociation (HCD) with a normalized collision energy of $30 \%$.

\section{Data Processing}

MALDI-TOF-MS spectra were analyzed using the FlexAnalysis software (version 3.4) to extract peaks and corresponding intensities. Then, Mascot search and sequence coverage calculation by allowing two missed cleavages were performed. LC-MS/MS raw data were analyzed using the MaxQuant software (version 1.6.17.0) to search against the UniPort Human database (updated on July 21, 2015). The main parameters were set as follows: (1) digestion mode was set as trypsin up to two missed cleavages allowed, (2) mass tolerances were $20 \mathrm{ppm}$ and 4.5 ppm for the first search and main search, respectively, (3) fixed modification, carbamidomethyl (C), (4) variable modification, deamidation $18 \mathrm{O}(\mathrm{N})$, acetyl (protein $\mathrm{N}$-term), oxidation $(\mathrm{M})$, (5) false discovery rate (FDR) was set as $\leq 0.01$ at the spectra, protein and modification levels, and (6) minimum and delta scores for the modified peptides were set as $\geq 40$ and $\geq 6$, respectively. For $\mathrm{N}$-glycopeptides identification, a motif filter of NXT/S/C (where X cannot be $\mathrm{P}$ ) in peptide sequence and a localization probability filter [deamidation $18 \mathrm{O}(\mathrm{N})$ ] of $\geq 0.75$ were applied.

\section{Characterization of TMF Materials}

Dynamic laser scattering (DLS) characterization was performed using a DynaPro NanoStar instrument (Wyatt Technology, Sta. Barbara, CA, USA). Fourier transform-infrared (FT-IR) spectra were obtained using a Tensor 27 FT-IR spectrometer (Bruker Corporation, Billerica, MA, USA). Vibrating sample magnetometry (VSM) was performed using a PPMS9 instrument (Quantum Design, San Diego, CA, USA). 
Thermogravimetric analysis (TGA) was performed using a SDT Q500 instrument (TA Instruments, New Castle, DE, USA).

\section{RESULTS AND DISCUSSION}

\section{Preparation and Characterization of TMF}

TMF was prepared via surface-initiated atom transfer radical polymerization (SI-ATRP) of the $\mathrm{Fe}_{3} \mathrm{O}_{4}$ nanoparticles (Supplementary Figure 1). First, the OA-coated $\mathrm{Fe}_{3} \mathrm{O}_{4}$ nanoparticles were synthesized according to the method, and then the initiators were immobilized on the surface of $\mathrm{Fe}_{3} \mathrm{O}_{4}$ nanoparticles through ligand exchange reaction. In SI-ATRP modification, NIPAM and UnAl were sequentially added into the reaction system to provide thermoresponsive property and aldenyde for enzyme conjugation. As a result, the polymer shell thickness, LCST, and the amounts of reactive groups can be well-defined by controlling the amounts and polymerization time of each monomer. After SI-ATRP modification, a multilayer enzyme reagent can be easily obtained by attaching enzymes on the side chains of the copolymer via the formation of covalent bonds with the aldehyde groups provided by poly-UnAl. More importantly, the poly-NIPAM part not only enables TMF well-dispersity in water to become magnetic fluid, which allows the digestion process under homogeneous conditions, but also offers a temperature-triggered method to separate the TMF-immobilized enzyme from the digestion medium. TMF was characterized by dynamic light scattering (DLS), FT-IR spectroscopy, VSM, and thermogravimetric analysis (TGA) to confirm the successful growth of PNIPAM- $b$-PUnAl copolymer chains on the surface of the magnetic nanoparticles and determine the content of the grafted copolymer chains.

Size and size distribution were characterized by DLS at $25^{\circ} \mathrm{C}$. The size of (a) un-grafted magnetic nanoparticles was $13.77 \mathrm{~nm}$, (b) that of Poly-NIPAM grafted magnetic nanoparticles was $27.99 \mathrm{~nm}$, and (c) that of PNIPAM- $b$-PUnAl copolymer grafted magnetic nanoparticles was $51.12 \mathrm{~nm}$. Their PDI were 0.282 , 0.430 , and 0.331, respectively (Figure 2A). The increase in size is caused by the grafting of poly-NIPAM and poly-UnAlon magnetic nanoparticles. FT-IR was performed on (a) un-grafted magnetic nanoparticles and (b) PNIPAM- $b$-PUnAl copolymer grafted magnetic nanoparticles (Figure 2B). The peaks at 592 $\mathrm{cm}^{-1}$ of both (a) and (b) are assigned to the $\mathrm{Fe}-\mathrm{O}$ bonds of the $\mathrm{Fe}_{3} \mathrm{O}_{4}$ core. Two relatively strong absorption peaks at 1,550 and $1,680 \mathrm{~cm}^{-1}$ corresponding to the $\mathrm{N}-\mathrm{H}$ and $\mathrm{C}=\mathrm{O}$ bonds in the amide groups of (b) indicate successful grafting of Poly-NIPAM on magnetic nanoparticles. A relatively weak absorption peak at $1,720 \mathrm{~cm}^{-1}$ ascribed to the $\mathrm{C}=\mathrm{O}$ bonds in the aldehyde group indicates successful growth of poly-UnAl on magnetic nanoparticles. A strong absorption peak at 2,920 $\mathrm{cm}^{-1}$ ascribed to the $\mathrm{C}-\mathrm{H}$ bond in the methylene group is observed in (b), which indicates that the polymer continuously grows on the surface of magnetic nanoparticles. Next, magnetic hysteresis loops for the magnetic $\mathrm{Fe}_{3} \mathrm{O}_{4}$ nanoparticles before and after grafting with the poly-NIPAM- $b$-poly-UnAl copolymer were determined by VSM testing (Figure 2C). The saturated magnetization (Ms) of un-grafted magnetic nanoparticles is 63.5 $\mathrm{emu} / \mathrm{g}$ and decreased to $37.8 \mathrm{emu} / \mathrm{g}$ after the SI-ATRP with
NIPAM and UnAl, because of the introduction of the unmagnetic copolymer. TGA analysis was carried out to further confirm the successful preparation of TMF as well as determine the content of surface-grafted polymer chains (Figure 2D). After thermo treatment over $700^{\circ} \mathrm{C}$, the thermally stable $\mathrm{Fe}_{3} \mathrm{O}_{4}$ core remains in the residue and decomposable polymer chains contribute to weight loss. Unmodified magnetic nanoparticles (a) show $<5 \%$ of total weight loss that might be attributed to the loss in water residue. In contrast, due to the decomposition of their polymer shell, modified magnetic nanoparticles showed noticeable weight loss. The weight loss is $21.7 \%$ for the magnetic nanoparticles with poly-NIPAM grafting (b) and increases to $32.85 \%$ after subsequent copolymerization with poly-UnAl (c), which indicates successful grafting of poly-NIPAM and polyUnAl parts on the surface of the $\mathrm{Fe}_{3} \mathrm{O}_{4}$ core. The enzyme loading capability of TMF was determined by HPLC measurement (Figure 2E). The peak area of the BSA solution with 0.5 $\mu \mathrm{g} / \mu \mathrm{l}$ (a) was 4,273 while the area decreased by $44 \%$ to 2,395 after attaching on 8-mg PNIPAM- $b$-PUnAl copolymer grafted magnetic nanoparticles; and, consequently, the concentration of the loading enzyme was $220 \mu \mathrm{g} / \mathrm{mg}$.

\section{Digestion Performance Evaluation of TMF Enzymes by Standard Protein}

First, we used BSA as a standard protein to examine the performance of TMF-immobilized trypsin. Besides, in-solution free trypsin digestion $\left(37^{\circ} \mathrm{C}, 16 \mathrm{~h}\right)$ was performed as a control. After digestion, TMF-trypsin was recovered by a heatingmagnet process, and the supernatant was collected for MALDITOF MS analysis. A typical MALDI-TOF-MS spectrum of BSA digests by TMF-trypsin digestion showed $89 \%$ peptide coverage (Figure 3A). No obvious peaks exceeding $3,000 \mathrm{~m} / \mathrm{z}$ could be detected, indicating that TMF-trypsin digestion was completed in such a short time. Moreover, no residual undigested BSA was observed, which demonstrated almost 100\% digestion by immobilized trypsin (Supplementary Figure 2). Reducing the amount of BSA to $10 \mu \mathrm{g}$, however, can still obtain higher sequence coverage $(87.67 \%)$ in TMF-trypsin system, and was relatively higher than that of free digestion (Figure 3B). Next, we used RNase B as a model $N$-glycoprotein to examine the performance of the TMF-immobilized PNGase F reagent. RNase $\mathrm{B}$ is a small glycoprotein with a molecular weight of $\sim 15 \mathrm{kDa}$ and containing a single $\mathrm{N}$-glycosylation site at Asn34, which possesses five to nine mannose residues attached to the chitobiose core ( $\mathrm{Fu}$ et al., 1994). RNase B was denatured at $95^{\circ} \mathrm{C}$ for $10 \mathrm{~min}$ and then digested with either TMF-PNGase F (room temperature, 3 min) or free PNGase F $\left(37^{\circ} \mathrm{C}, 16 \mathrm{~h}\right)$. Five $N$-glycans [(Man)5-(Man)9] were identified in both conditions with similar signal intensity, indicating the deglycosylation efficiency of the immobilized PNGase F was as good as that of the free PNGase F digestion (Figures 3C,D), but with 320 a fold reduced digestion time. Next, the completeness of deglycosylation using TMF-PNGase $\mathrm{F}$ was examined by MALDI-TOF MS in the leaner model. Multiple peaks were detected within the range from 14,984.7 to $15,832.7 \mathrm{Da}$ before digestion of RNase B because of the microheterogeneity of $\mathrm{N}$-glycosylation; while only one peak 


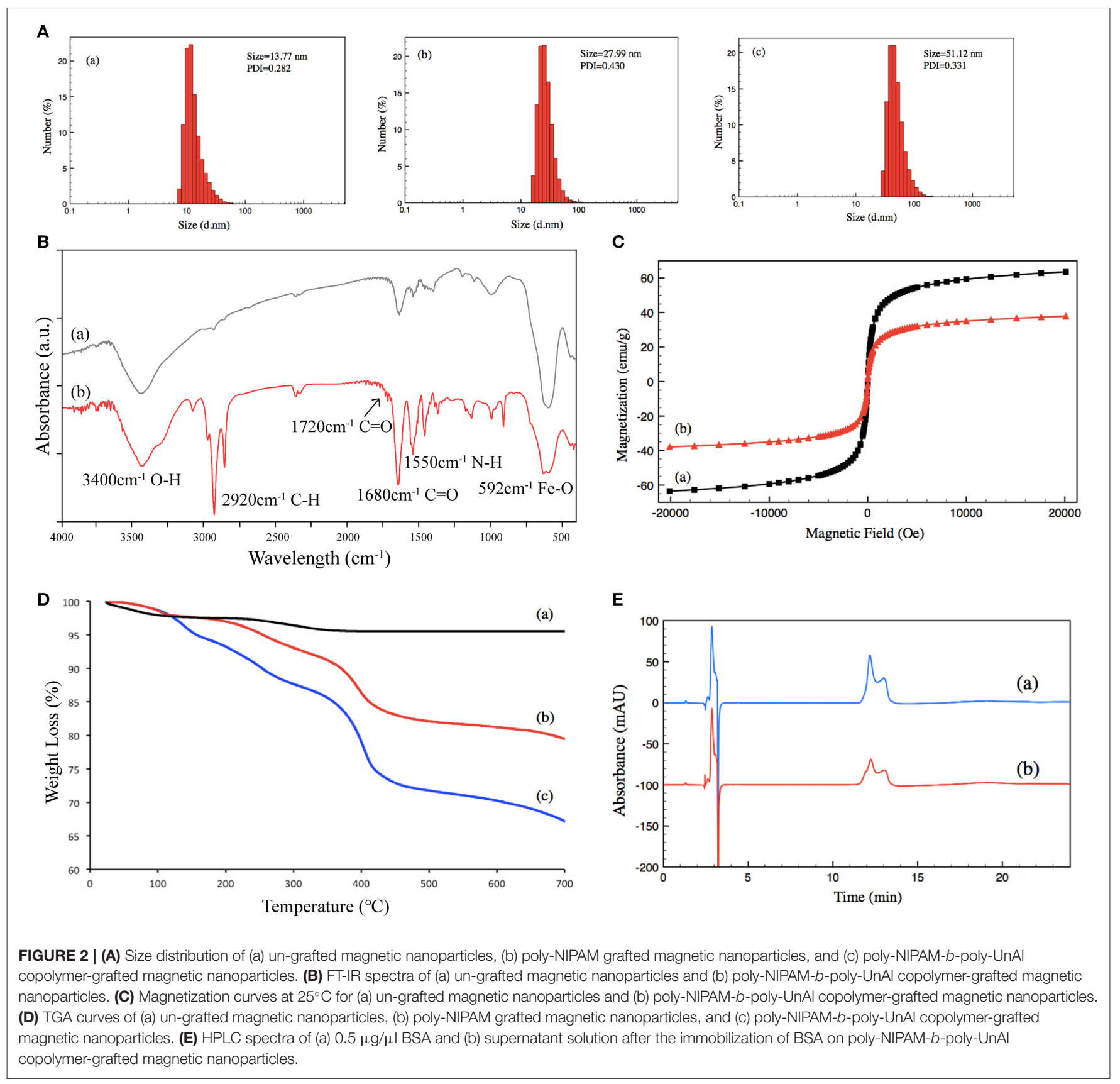

at 13758.5 Da was detected after TMF-PNGase F digestion, indicating complete removal of the $N$-glycans by TMF-PNGase F (Figure 3E). Collectively, the TMF-immobilized enzymes (both trypsin and PNGase F) can efficiently digest (glyco)proteins using significantly reduced time compared to the conventional in-solution digestion system.

\section{The Combinational Usage of TMF-Trypsin and TMF-PNGase $F$ for Ultrafast Urine $\mathbf{N}$-Glycoproteome Analysis}

Long sample processing time and low throughput of conventional in-solution digestion is one of the major limitations for the application of (glyco)proteomic technique in large-scale clinical studies. Using an immobilized enzyme is a promising solution. Unlike other reported immobilized enzymes, TMF-immobilized enzymes have the advantage of homogeneous-phase digestion and heterogeneous separation. Therefore, efficient digestion can be expected by avoiding high-mass transfer resistance in the two-phase digestion system using solid material-immobilized enzymes. Furthermore, TMF-immobilized enzymes can be easily separated from digestion products and recovered through heat-trigged flocculation and magnetic separation. We further evaluated digestion efficiency by sequential application of TMFtrypsin and TMF-PNGase F in urine glycoproteome analysis 


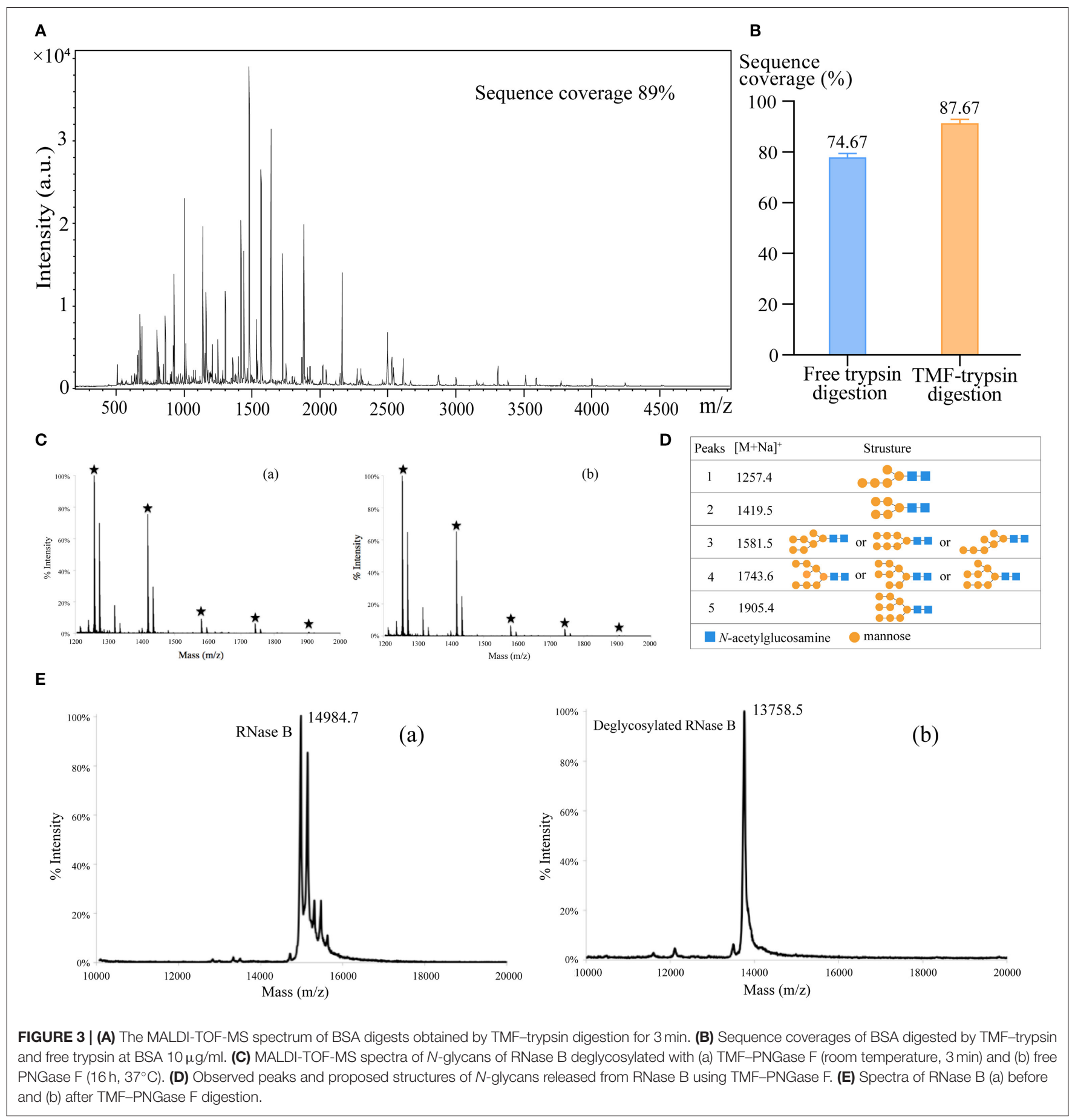

(Figure 1). After TMF-trypsin digestion of urine proteins, the peptides were subjected to $N$-glycopeptides enrichment by hydrophilic interaction liquid chromatography (HILIC) (Mysling et al., 2010; Cong et al., 2017). The $N$-glycopeptides are further subjected to deglycosylation with TMF-PNGase $\mathrm{F}$ in the $\mathrm{H}_{2}^{18} \mathrm{O}$ system. The ${ }^{18} \mathrm{O}$-labeled $\mathrm{N}$-glycopeptides were collected for mass spectrometry analysis. With TMFenzymes, the total sample processing time from urine protein digestion to MS analysis is about $1 \mathrm{~h}$, which is at least 20 times faster than that with in-solution free enzyme digestion. Impressively, both TMF-trypsin and TMFPNGase $\mathrm{F}$ digestion identified more unique proteins and peptides than in-solution digestion (Figures 4A,D). Compared with 793 protein groups and 4,718 peptides identified by free trypsin digestion (Supplementary Tables 1, 2), TMFtrypsin digestion yielded a slight increase in the number 


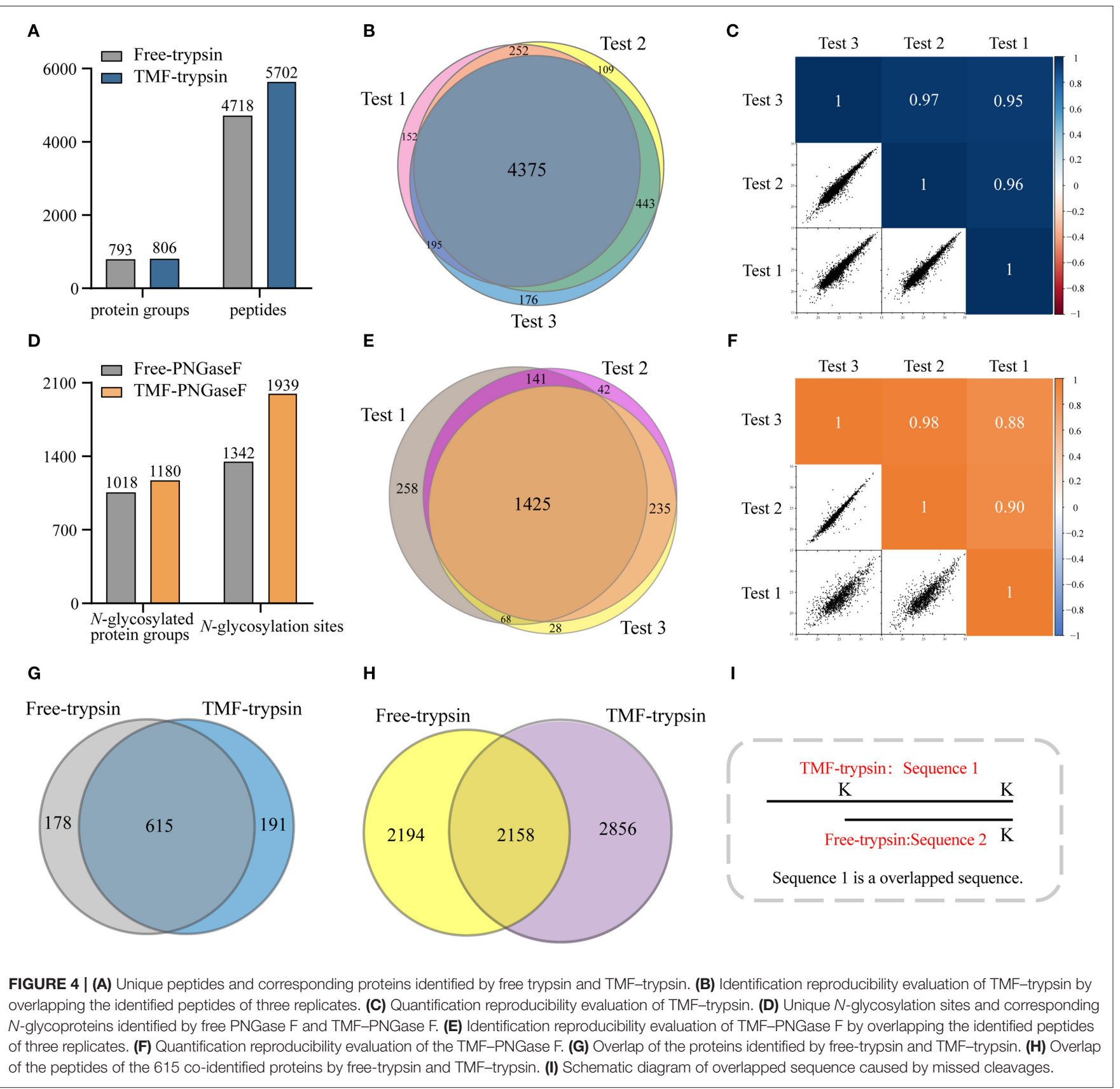

of protein groups and peptides, which is 806 and 5,702, respectively (Supplementary Tables 3, 4). TMF-PNGase $\mathrm{F}$ also had a better performance, identifying $1,180 \mathrm{~N}$ glycosylated protein groups and 1,939 $\mathrm{N}$-glycosylation sites (Supplementary Tables 7, 8), while free PNGase F digestion identified 1,018 $\mathrm{N}$-glycosylated protein groups and 1,342 Nglycosylation sites (Supplementary Tables 5, 6). Furthermore, we conducted three technical replicates to evaluate the reproducibility of the two TMF-immobilized enzymes. In TMF-trypsin digestion, $96 \%$ peptides were obtained in at least two tests. Likewise, $\sim 88 \%$ of $N$-glycopeptides were identified in at least two tests of TMF-PNGase F digestion (Figures 4B,E).
Digestion products of both TMF-immobilized enzymes also have good quantitative reproducibility, with Pearson correlation coefficients higher than 0.95 for peptides and 0.88 for $N$ glycopeptides (Figures 4C,F), demonstrating their capability for actual application in complex samples.

We noticed that relatively more missed cleavage peptides were found in the digestion product of TMF-trypsin, which is disadvantageous for protein quantification. To further evaluate the digestion effect of TMF-trypsin, we analyzed the peptides in the 615 co-identified proteins by the two digestion methods (Figure 4G). Among the 2,856 peptides uniquely identified by TMF-trypsin digestion, 1,089 peptides were with partial 
sequence overlapping with the corresponding peptides in the free-trypsin digestion product (Figure $4 \mathbf{H}$ ) because of missed cleavages (Figure 4I). These partial overlapping peptides provide a little contribution to protein identification. However, for the rest of the 1,767 uniquely identified peptides obtained by TMF-trypsin, their amino acid sequences are completely different from those in the digestion product of free-trypsin, which is advantageous in improving the sequence coverage in protein identification. Analysis of amino acids sequence coverage of the co-identified proteins led to similar results. Of the 615 co-identified proteins, $\sim 60 \%$ have higher amino acids sequence coverage at the protein level in the TMFtrypsin digestion product. Furthermore, both free trypsin and TMF-trypsin provided a large number of uniquely identified peptides that were not covered by each other. Therefore, combined application of these two digestion methods may lead to increased protein sequence coverage and improved identification reliability, especially for the low abundant proteins, which usually only have a few or no unique peptides identified using only the free-trypsin digestion.

\section{CONCLUSION}

A novel thermoresponsive magnetic fluid (TMF)-immobilized enzyme (trypsin or PNGase F) for ultrafast and highly efficient proteome digestion and glycopeptide deglycosylation was developed in this study. The high-water dispersity and heat-triggered magnetic separation of TMF-immobilized enzymes make them capable of homogeneous digestion and heterogeneous separation. Therefore, highly efficient and rapid protein digestion and glycopeptide deglycosylation were achieved by avoiding mass transfer resistance in the heterogeneous system, and facile sample recovery was achieved by thermoflocculation and magnetic force. Taking advantage of these unique features, TMF-immobilized enzymes led to the identification of $\sim 2,000 \mathrm{~N}$-glycopeptides in human urine sample and, with more than 20 times reduction in sample processing

\section{REFERENCES}

Cong, Y., Hu, L., Zhang, Z., Gao, Y., Dong, M., Qin, H., et al. (2017). Analysis of therapeutic monoclonal antibody glycoforms by mass spectrometry for pharmacokinetics study. Talanta 165, 664-670. doi: 10.1016/j.talanta.2017.01.023

Dong, M., Lih, T. M., Chen, S. Y., Cho, K. C., Eguez, R. V., Hoti, N., et al. (2020). Urinary glycoproteins associated with aggressive prostate cancer. Theranostics 10, 11892-11907. doi: 10.7150/thno.47066

Fauser, J., Savitskiy, S., Fottner, M., Trauschke, V., and Gulen, B. (2020). Sortasemediated quantifiable enzyme immobilization on magnetic nanoparticles. Bioconjug. Chem. 31, 1883-1892. doi: 10.1021/acs.bioconjchem.0c00322

Fu, D., Chen, L., and O’Neill, R. A. (1994). A detailed structural characterization of ribonuclease $B$ oligosaccharides by $1 \mathrm{H}$ NMR spectroscopy and mass spectrometry. Carbohydr. Res. 261, 173-186. doi: 10.1016/0008-6215(94)84015-6

Hart, G. W., and Copeland, R. J. (2010). Glycomics hits the big time. Cell 143, 672-676. doi: 10.1016/j.cell.2010.11.008

Huang, J., Dong, J., Shi, X., Chen, Z., Cui, Y., Liu, X., et al. (2019). Dual-functional titanium(IV) immobilized metal affinity chromatography time, demonstrated the potential use of this strategy for fast and high throughput analysis of $\mathrm{N}$-glycoproteome in clinical samples.

\section{DATA AVAILABILITY STATEMENT}

The datasets presented in this study can be found in online repositories. The names of the repository/repositories and accession number(s) can be found at: ProteomeXchange Consortium via the PRIDE partner repository with the dataset identifier PXD024639.

\section{AUTHOR CONTRIBUTIONS}

WQ conceived the project. ZF, TL, and FZ designed the experiments and interpreted data. ZF carried out the synthesis of TMF-immobilized enzymes (trypsin or PNGase F) and performed urinary protein exaction, proteomics experiments, and MS analysis. TL and FZ performed characterization of TMF. ZF and TL performed digestion performance evaluation of TMF-immobilized enzymes. All authors commented on the manuscript.

\section{FUNDING}

This work was supported by the National Key R\&D Program of China (Grant nos: 2018YFC0910302, 2017YFA0505002, and 2017YFC0906703), National Natural Science Foundation of China (Grant no: 21904008), National Key Laboratory of Proteomics (Grant no: SKLP-K201706), and Innovation Foundation of Medicine (Grant no: 20SWAQX34).

\section{SUPPLEMENTARY MATERIAL}

The Supplementary Material for this article can be found online at: https://www.frontiersin.org/articles/10.3389/fchem. 2021.676100/full\#supplementary-material approach for enabling large-scale profiling of protein mannose-6-phosphate glycosylation and revealing its predominant substrates. Anal. Chem. 91, 11589-11597. doi: 10.1021/acs.analchem.9b01698

Krenkova, J., Lacher, N. A., and Svec, F. (2009). Highly efficient enzyme reactors containing trypsin and endoproteinase LysC immobilized on porous polymer monolith coupled to MS suitable for analysis of antibodies. Anal. Chem. 81, 2004-2012. doi: 10.1021/ac8026564

Létant, S. E., Hart, B. R., Kane, S. R., Hadi, M. Z., Shields, S. J., and Reynolds, J. G. (2004). Enzyme immobilization on porous silicon surfaces. Adv. Mater. 16, 689-693. doi: 10.1002/adma.200306173

Luo, J., Marpani, F., Brites, R., Frederiksen, L., Meyer, A. S., Jonsson, G., et al. (2014). Directing filtration to optimize enzyme immobilization in reactive membranes. J. Memb. Sci. 459, 1-11. doi: 10.1016/j.memsci.2014.01.065

Mateo, C., Palomo, J. M., Fernandez-Lorente, G., Guisan, J. M., and FernandezLafuente, R. (2007). Improvement of enzyme activity, stability and selectivity via immobilization techniques. Enzyme Microb. Technol. 40, 1451-1463. doi: 10.1016/j.enzmictec.2007.01.018

Mereiter, S., Balmana, M., Campos, D., Gomes, J., and Reis, C. A. (2019). Glycosylation in the era of cancer-targeted therapy: where are we heading? Cancer Cell 36, 6-16. doi: 10.1016/j.ccell.2019.06.006 
Mysling, S., Palmisano, G., Højrup, P., and Thaysen-Andersen, M. (2010). TFA- utilizing ion-pairing hydrophilic interaction chromatography solid phase extraction for efficient glycopeptide enrichment in glycoproteomics. Anal. Chem. 82, 5598-5609. doi: 10.1021/ac100530w

Pan, J., Hu, Y., Sun, S., Chen, L., Schnaubelt, M., Clark, D., et al. (2020). Glycoproteomics-based signatures for tumor subtyping and clinical outcome prediction of high-grade serous ovarian cancer. Nat. Commun. 11:6139. doi: 10.1038/s41467-020-19976-3

Qin, W., Song, Z., Fan, C., Zhang, W., Cai, Y., Zhang, Y., et al. (2012). Trypsin immobilization on hairy polymer chains hybrid magnetic nanoparticles for ultra fast, highly efficient proteome digestion, facile 180 labeling and absolute protein quantification. Anal. Chem. 84, 3138-3144. doi: 10.1021/ac2029216

Schjoldager, K. T., Narimatsu, Y., Joshi, H. J., and Clausen, H. (2020). Global view of human protein glycosylation pathways and functions. Nat. Rev. Mol. Cell Biol. 21, 729-749. doi: 10.1038/s41580-020-00294-x

Sharifi, M., Sohrabi, M. J., Hosseinali, S. H., Hasan, A., Kani, P. H., Talaei, A. J., et al. (2020). Enzyme immobilization onto the nanomaterials: application in enzyme stability and prodrug-activated cancer therapy. Int. J. Biol. Macromol. 143, 665-676. doi: 10.1016/j.ijbiomac.2019.12.064

Stadlmann, J., Taubenschmid, J., Wenzel, D., Gattinger, A., Durnberger, G., Dusberger, F., et al. (2017). Comparative glycoproteomics of stem cells identifies new players in ricin toxicity. Nature 549, 538-542. doi: $10.1038 /$ nature 24015

Sun, Y., Ding, X., Zheng, Z., Cheng, X., Hu, X., and Peng, Y. (2006). Magnetic separation of polymer hybrid iron oxide nanoparticles triggered by temperature. Chem. Commun. 26, 2765-2767. doi: 10.1039/b604202c

$\mathrm{Wu}$, J., and Gao, Y. (2015). Physiological conditions can be reflected in human urine proteome and metabolome. Expert Rev. Proteomics 12, 623-636. doi: 10.1586/14789450.2015.1094380

Yang, G., Hoti, N., Chen, S. Y., Zhou, Y., Wang, Q., Betenbaugh, M., et al. (2020). One-step enrichment of intact glycopeptides from glycoengineered Chinese hamster ovary cells. Front. Chem. 8:240. doi: 10.3389/fchem.2020.0 0240
Yuan, H., Zhang, S., Zhao, B., Weng, Y., Zhu, X., Li, S., et al. (2017). Enzymatic reactor with trypsin immobilized on graphene oxide modified polymer microspheres to achieve automated proteome quantification. Anal. Chem. 89, 6324-6329. doi: 10.1021/acs.analchem.7b00682

Yuce-Dursun, B., Cigil, A. B., Dongez, D., Kahraman, M. V., Ogan, A., and Demir, S. (2016). Preparation and characterization of sol-gel hybrid coating films for covalent immobilization of lipase enzyme. J. Mol. Catal. B Enzymatic 127, 18-25. doi: 10.1016/j.molcatb.2016.02.007

Zhang, W., Liu, T., Dong, H., Bai, H., Tian, F., Shi, Z., et al. (2017). Synthesis of a highly azide-reactive and thermosensitive biofunctional reagent for efficient enrichment and large-scale identification of O-GlcNAc proteins by mass spectrometry. Anal. Chem. 89, 5810-5817. doi: 10.1021/acs.analchem.6b04960

Zhao, M., Li, M., Yang, Y., Guo, Z., Sun, Y., Shao, C., et al. (2017). A comprehensive analysis and annotation of human normal urinary proteome. Sci. Rep. 7:3024. doi: 10.1038/s41598-017-03226-6

Zhao, M., Zhang, X., and Deng, C. (2015). Rational synthesis of novel recyclable $\mathrm{Fe}(3) \mathrm{O}(4) @ \mathrm{MOF}$ nanocomposites for enzymatic digestion. Chem. Commun. 51, 8116-8119. doi: 10.1039/C5CC01908G

Zhao, T., Jia, L., Li, J., Ma, C., Wu, J., Shen, J., et al. (2020). Heterogeneities of sitespecific N-glycosylation in HCC tumors with low and high AFP concentrations. Front. Oncol. 10:496. doi: 10.3389/fonc.2020.00496

Conflict of Interest: The authors declare that the research was conducted in the absence of any commercial or financial relationships that could be construed as a potential conflict of interest.

Copyright (C) 2021 Fan, Liu, Zheng, Qin and Qian. This is an open-access article distributed under the terms of the Creative Commons Attribution License (CC BY). The use, distribution or reproduction in other forums is permitted, provided the original author(s) and the copyright owner(s) are credited and that the original publication in this journal is cited, in accordance with accepted academic practice. No use, distribution or reproduction is permitted which does not comply with these terms. 